\title{
Recruitment of the Kainate Receptor Subunit Glutamate Receptor 6 by Cadherin/Catenin Complexes
}

\author{
Françoise Coussen, ${ }^{1}$ Elisabeth Normand, ${ }^{1}$ Cécile Marchal, ${ }^{1}$ Pierre Costet, ${ }^{2}$ Daniel Choquet, ${ }^{1}$ \\ Mireille Lambert, ${ }^{3}$ René-Marc Mège, ${ }^{3}$ and Christophe Mulle ${ }^{1}$ \\ ${ }^{1}$ Centre National de la Recherche Scientifique Unité Mixte de Recherche 5091, Institut François Magendie and \\ ¿Laboratoire de Transgénèse Université Bordeaux 2, Bordeaux 33077, France, and 3/nstitut National de la Santé et de la \\ Recherche Médicale U440, Institut du Fer à Moulin, Paris 75005, France
}

Kainate receptors modulate synaptic transmission by acting either at presynaptic or at postsynaptic sites. The precise localization of kainate receptors as well as the mechanisms of targeting and stabilization of these receptors in neurons are largely unknown. We have generated transgenic mice expressing the kainate receptor subunit glutamate receptor 6 (GluR6) bearing an extracellular myc epitope (myc-GluR6), in forebrain neurons, in which it assembles with endogenous kainate receptor subunits. In transgenic mice crossed with GluR6-deficient mice, myc-GluR6 efficiently rescues the missing subunit. Immunoprecipitation of transgenic brain extracts with anti-myc antibodies demonstrates an interaction with cadherins, $\beta$-catenin, and p120 catenin, as well as with the associated proteins calcium calmodulin-dependent serine kinase and Velis, but not with $\alpha$-catenin. In glutathione S-transferase-pulldown experiments, $\beta$-catenin interacts, although indirectly, with the last 14 aa of GluR6. Transfected myc-GluR6 colocalizes with $\beta$-catenin at cellcell junctions in non-neuronal cells. Finally, activation of $\mathrm{N}$-cadherins by ligand-covered latex beads recruits GluR6 to cadherin/catenin complexes. These results suggest an important role for cadherin/catenin complexes in the stabilization of kainate receptors at the synaptic membrane during synapse formation and remodeling.

Key words: kainate receptors; cadherin/catenin complexes; transgenic mice; synaptic organization; protein-protein interactions; CASK/Veli complexes
Kainate receptors (KARs) display a large variety of physiological functions in synaptic transmission and in its regulation. Based on electrophysiological studies, KARs are thought to be in part localized presynaptically on axons or axon terminals, where they modulate transmitter release or axonal excitability. KARs also participate in synaptic transmission at a postsynaptic level (for review, see Chittajalu et al., 1999; Lerma et al., 2001), although KAR-mediated EPSCs display unexpected kinetic properties (Castillo et al., 1997; Vignes and Collingridge, 1997; Mulle et al., 1998; Bureau et al., 2000). The differences in synaptic properties between AMPA receptor (AMPAR)- and KAR-EPSCs could be explained by a different localization of both types of receptors. Hypothetically, KARs would be located at a further distance from glutamate release sites than AMPARs (Castillo et al., 1997; Bureau et al., 2000) in a perisynaptic region and would then be activated by a low, nonsaturating concentration of glutamate, explaining both the slow kinetics and summation properties. Although AMPA and NMDA receptors (NMDARs) are known to be concentrated in the postsynaptic density (PSD), precise data on the subcellular localization of KARs are lacking. The molecular mechanisms by which AMPA and NMDA receptors are

Received Oct. 10, 2001; revised April 30, 2002; accepted May 2, 2002.

This work was supported by the Centre National de la Recherche Scientifique, the French Ministère de la Recherche, the Conseil Régional Aquitaine (to C.M.), the Association pour la Recherche sur le cancer (to R.-M.M.), and the Association Française contre les Myopathies (to R-M.M.). We thank Agnès Hémar for comments on this manuscript, Richard Schwartzmann (Université Paris VI) for his help with the confocal microscope, Dr. Carla Perego for the gift of antibodies and helpf ul advice, and Drs. Kaibuchi and Nagafuchi for the gift of Mal- $\beta$-catenin cDNA.

Correspondence should be addressed to Christophe Mulle, Centre National de la Recherche Scientifique Unité Mixte de Recherche 5091, Institut François Magendie, Bordeaux 33077, France. E-mail: mulle@u-bordeaux2.fr.

Copyright (C) 2002 Society for Neuroscience $0270-6474 / 02 / 226426-11 \$ 15.00 / 0$ targeted and stabilized in the PSD (Sheng and Pak, 2000) involve protein-protein interactions between the C-terminal domain of AMPA and NMDA receptors and PSD-95/discs-large/zona occludens-1 (PDZ) domain proteins found in the PSD (for review, see Sheng and Pak, 2000). AMPA and NMDA receptors bind to distinct sets of PDZ domain proteins. This difference probably accounts for the differential synaptic regulation of AMPA and NMDA receptors. In addition, binding of glutamate receptor 2 (GluR2) to $N$-ethylmaleimide-sensitive factor, a protein involved in vesicle trafficking and membrane fusion, is involved in the recycling of AMPARs (Nishimune et al., 1998; Osten et al., 1998). In neurons, distinct subtypes of glutamate receptors are thus segregated both topographically and functionally through interactions with different protein complexes.

Little is known about the interactions between KARs and intracellular proteins and even less about their targeting and stabilization in specific subdomains of the neuronal membrane. The subunit composition of KARs, which are thought to assemble in a tetrameric stoichiometry, could be very diverse, given the large combinatorial possibilities suggested by KAR subunit mRNA distribution (Wisden and Seeburg, 1993; Bischoff et al., 1997) and functional expression studies (for review, see Bettler and Mulle, 1995; Chittajalu et al., 1999; Lerma et al., 2001). It is not known how this large variety of subunit combinations relates to the distinct subcellular localizations of KARs. GluR6 and KA2 interact with PSD-95 and synapse-associated protein 102, PDZ domain proteins from the PSD, both in vivo and in vitro (Garcia et al., 1998; Mehta et al., 2001), promoting clustering of KARs in heterologous expression systems. These data suggest the presence of GluR6/KA2 KARs in the PSD. Based on electrophysiological analysis of GluR6-deficient mice, it is known however that 
GluR6-containing receptors are present at a presynaptic level (Contractor et al., 2000; Mulle et al., 2000) as well as at a postsynaptic level (Mulle et al., 1998; Bureau et al., 2000). It is likely that localization and stabilization of GluR6-containing KARs in distinct subdomains of the neuronal membrane require specific interaction with distinct sets of proteins.

The postsynaptic membrane facing the transmitter release zone is bordered by a perisynaptic region enriched in cadherin/catenin adhesion proteins, as shown by immunogold electron microscopic studies (Uchida et al., 1996). Because this region hypothetically contains synaptically activated KARs, we examined the possibility that KARs could interact with cadherin/catenin complexes. Cadherins are a family of homophilic cell-adhesion receptors that are crucial for intercellular association of most cell types (Takeichi, 1988; Shapiro and Colman, 1999; Bruses, 2000; Tepass et al., 2000). Cadherins associate with intracellular actin filaments via proteins termed catenins. Although cadherins form a large family of proteins, $\beta$-catenin binds directly to the $\mathrm{C}$-terminal cytoplasmic tail of all known "classical" cadherins. Here, we demonstrate that KARs interact with proteins of the cadherin/catenin complex. These data open the possibility that during synapse formation and synaptic plasticity, activation of cadherins recruits GluR6 KAR to cadherin/catenin complexes.

\section{MATERIALS AND METHODS}

Generation and maintenance of transgenic mice. Six consecutive c-myc epitopes were introduced after the signal sequence of rat GluR6 cDNA. The total six myc-GluR6 construct was inserted in front of the $\mathrm{Ca}^{2+}$ calmodulin-dependent protein kinase II $(\mathrm{CaMKII} \alpha)$ promoter $(8.5 \mathrm{~kb})$ (vectors pNN-265 and pMM-403; gifts from I. Mansuy, Neuroscience Center, Zürich, Switzerland) (Mayford et al., 1996). Transgenic mice were generated by microinjection of the linear construct into fertilized eggs collected from $\mathrm{C} 57 \mathrm{BL} / 6 / \mathrm{CBA} \mathrm{F}_{1} / \mathrm{J}$ superovulated females mated with $\mathrm{C} 57 \mathrm{BL} / 6 / \mathrm{CBA} \mathrm{F}_{1}$ males. Six transgenic founders were obtained and crossed with C57BL/6 mice to produce the CaMKII $\alpha$-myc-GluR6 transgenic lines. Myc-GluR6 transgenic mice were crossed with GluR6 (Mulle et al., 1998) mice to produce the CaMKII $\alpha$-myc-GluR6 $\times$ GluR6 $^{-1-}$ transgenic line.

Immunocytochemistry. Cultured rat hippocampal neurons were prepared from 18-d-old rat embryos according to previously published methods (Hemar et al., 1997) and used after $12 \mathrm{~d}$ in culture. COS-7 and human embryonic kidney (HEK)-293 cells were transfected with the various cDNAs using the Fugene kit (Roche Diagnostics, Meylan, France) and hippocampal neurons with the Effecten kit (Qiagen, Courtaboeuf, France). For surface labeling of myc-GluR6, cells were incubated for $20 \mathrm{~min}$ at $20^{\circ} \mathrm{C}$ with anti-myc tag antibodies (1/100th dilution) in culture media and immediately fixed with $4 \%$ paraformaldehyde and $4 \%$ sucrose for $15 \mathrm{~min}$ at $37^{\circ} \mathrm{C}$. For intracellular labeling, cells were fixed, permeabilized with $0.3 \%$ Triton $\mathrm{X}-100$ for $2 \mathrm{~min}$, and rinsed in PBS/ $0.3 \%$ BSA. Primary antibodies were incubated for $30 \mathrm{~min}$ at room temperature and washed with PBS/BSA, and the secondary fluorescent antibodies (anti-mouse antibody, Alexa 568; anti-rabbit antibody, Alexa 488) were incubated for $30 \mathrm{~min}$ at $20^{\circ} \mathrm{C}$ and extensively washed with PBS/BSA. Coverslips were then mounted with a Prolong antifade kit from Molecular Probes (Eugene, OR). Pictures were taken with an Axioplan2 microscope (Zeiss, Le Pecq, France).

Electrophysiology. Whole-cell patch-clamp recordings of CA3 pyramidal cells and stimulation of mossy fibers were performed in parasagittal brain slices (350 $\mu \mathrm{m}$ thick) from mice aged $17-20 \mathrm{~d}$ as described previously (Mulle et al., 1998).

Preparation of brain lysate. For each experiment, three mouse brains were homogenized in $15 \mathrm{ml}$ of homogenization buffer, which contained (in mM): $20 \mathrm{HEPES}, 0.15 \mathrm{EDTA}$, and $10 \mathrm{KCl}, \mathrm{pH} 7.5$, supplemented with a cocktail of protease inhibitors (aprotinin, leupeptin, pepstatin-A, and pefabloc, $10 \mu \mathrm{g} / \mathrm{ml}$ ), and centrifuged for $10 \mathrm{~min}$ at $2500 \mathrm{rpm}$. The supernatant was centrifuged for $30 \mathrm{~min}$ at $13,000 \mathrm{rpm}$. The pellet was homogenized with 20 strokes in $15 \mathrm{ml}$ of the same buffer adjusted at $15 \%$ sucrose. The homogenate was centrifuged for $10 \mathrm{~min}$ at $2500 \mathrm{rpm}$ to remove genomic DNA. The supernatant containing the membranes was centrifuged again for $30 \mathrm{~min}$ at $13,000 \mathrm{rpm}$. Brain membranes were solubilized in a medium containing $20 \mathrm{~mm}$ HEPES, $1 \%$ Triton X-100, $150 \mathrm{~mm} \mathrm{NaCl}$, and $0.15 \mathrm{~mm}$ EDTA, pH 7.5, and an antiprotease cocktail with 20 dunces and then incubated for $1 \mathrm{hr}$. The sample was centrifuged for $45 \mathrm{~min}$ at $13,000 \mathrm{rpm}$. All steps were performed at $4^{\circ} \mathrm{C}$. Protein concentration was evaluated with a Bio-Rad (Richmond, CA) assay.

Immunoprecipitation experiments. Triton X-100 supernatant $(1.5 \mathrm{ml})$ was incubated with $50 \mu \mathrm{l}$ of protein-G Sepharose for $40 \mathrm{~min}$ at $4^{\circ} \mathrm{C}$ and centrifuged. The cleared supernatant was then incubated with the specific antibodies $(3 \mu \mathrm{l})$ for $1 \mathrm{hr}$ at $4^{\circ} \mathrm{C}$ and then incubated overnight with $50 \mu \mathrm{l}$ of protein-G Sepharose at $4^{\circ} \mathrm{C}$. Resin was washed with $2 \mathrm{ml}$ of loading buffer and $2 \mathrm{ml}$ of the same buffer containing $500 \mathrm{~mm} \mathrm{NaCl}$. Beads were resuspended in $60 \mu \mathrm{l}$ of gel loading buffer, separated by $7.5 \%$ SDS-PAGE, and immunoblotted with the appropriate antibodies. Quantitative analysis of Western blots was performed using Metamorph software (Universal imaging, Dawnington, PA).

Glutathione S-transferase-pulldown assay. cDNA sequences encoding the rat C-terminal GluR6 subunit (starting at the amino acid 838) were amplified by PCR from the original clone using primers that generated $B a m \mathrm{HI}$ and EcoRI restriction sites at their ends. These PCR products were then subcloned in pGex-4T-1 (Amersham Biosciences, Les Ulis, France). Proteins were induced by $0.2 \mathrm{~mm}$ isopropyl- $\beta$-D-thiogalactopyranoside at $20^{\circ} \mathrm{C}$ for $1 \mathrm{hr}$. After extraction, proteins were bound on glutathione $S$-transferase (GST)-Sepharose. The amount of bound proteins was estimated by Coomassie blue staining and by immunoblot with anti-GluR6 antibody when possible.

Triton X-100 brain extracts $(1.5 \mathrm{ml})$ were incubated with $10 \mu \mathrm{g}$ of GST, GST-R6-C $\Delta 14$, GST-R6-C $\Delta 4$, or GST-R6-Ctotal immobilized on GSTSepharose. Beads were washed with $2 \mathrm{ml}$ of loading buffer and $2 \mathrm{ml}$ of the same buffer containing $500 \mathrm{~mm} \mathrm{NaCl}$. Beads were resuspended in $60 \mu \mathrm{l}$ of loading buffer, resolved by SDS-PAGE, and immunoblotted with the appropriate antibodies.

For direct binding assay, PSD-95 protein (PDZ domain 1-2; amino acids 1-309) was expressed in bacteria, purified on glutathione-Sepharose beads, and cut with thrombin overnight at $4^{\circ} \mathrm{C}$. Mal- $\beta$-catenin was produced in Escherichia coli and extracted with Triton X-100. Mal- $\beta$ catenin was incubated with GST-N-cadherin (Ncad) intracellular domain, GST-R6-C-terminal domain, or GST-R6-C 114 resins. As a positive control, PSD-95 protein was incubated with GST-R6-C-terminal domain resin. Proteins were incubated with the different GST proteins for $2 \mathrm{hr}$ at room temperature, washed for immunoprecipitation experiments, resolved by SDS-PAGE, and immunoblotted with the appropriate antibodies.

Ncad-Fc experiments. Ncad-Fc protein production and bead preparation were performed as in Lambert et al. (2000) using Ncad-Fc protein or anti-myc antibody. For bead cell-adhesion assay, C2 cells were seeded at a density of 8000 cells $/ \mathrm{cm}^{2}$ on a three well glass slide and cultured for 24 $\mathrm{hr}$. One microliter of sonicated beads was added to each well in $250 \mathrm{ml}$ of DMEM and $10 \%$ FCS and placed in the incubator $\left(5 \% \mathrm{CO}_{2}, 37^{\circ} \mathrm{C}\right)$ for $45 \mathrm{~min}$. After washes, cells were fixed with $3 \%$ formaldehyde in PBS, washed with PBS and $0.1 \mathrm{M}$ glycine, permeabilized with $0.5 \%$ Triton $\mathrm{X}-100$ in PBS for $5 \mathrm{~min}$, and submitted for antibody revelation.

Antibodies. The following antibodies were used: monoclonal anti-myc (clone 9E10; Roche Diagnostics); polyclonal anti-myc (06-549), antiGluR6/7 (06-309), anti-KA2 (06-315), and anti-PSD-95 family (05-427) (Upstate Biotechnology, Lake Placid, NY); anti- $\beta$-catenin (C-2206), anti- $\alpha$-catenin (C-2081), and anti-pan-cadherin (C-1821) (Sigma, St. Quentin Fallavier, France); CASK [monoclonal antibody (mAb) 5230] and anti-GluR2 (mAb 397) (Chemicon, Temecula, CA); anti-Veli (V20920; Transduction Laboratories, Lexington, KY); anti-GST (274577-01; Amersham Biosciences); anti-synaptophysin (MON 9013; Monosan, Uden, The Netherlands); and anti-p120 catenin (made by R. M. Mège).

\section{RESULTS}

\section{Generation of transgenic mice expressing epitope-tagged myc-GluR6}

Intracellular proteins interacting with AMPA or NMDA receptors have in general been identified by yeast-two-hybrid screening techniques using the intracellular $\mathrm{C}$ terminal as a bait. This technique has not yet been fruitful in the case of KARs. To begin exploration of proteins involved in the stabilization and trafficking of KARs, we have attempted to directly assess interaction of GluR6-containing receptors with identified proteins of the cad- 
A

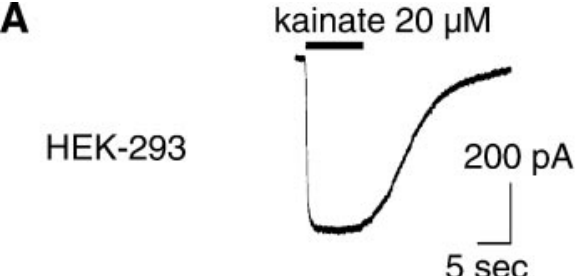

B

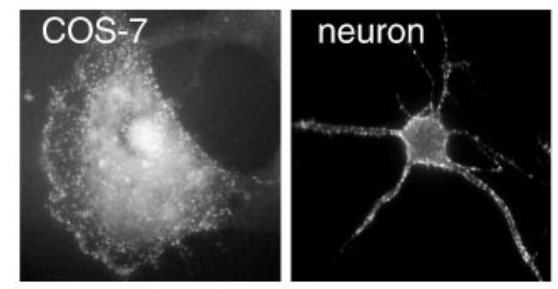

C

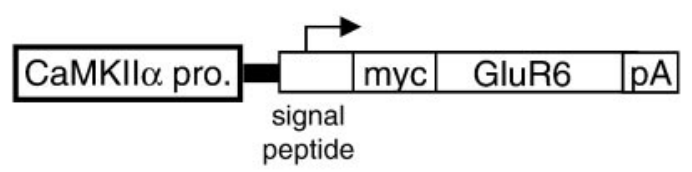

D Line 23 Line 26

Line 28 WT

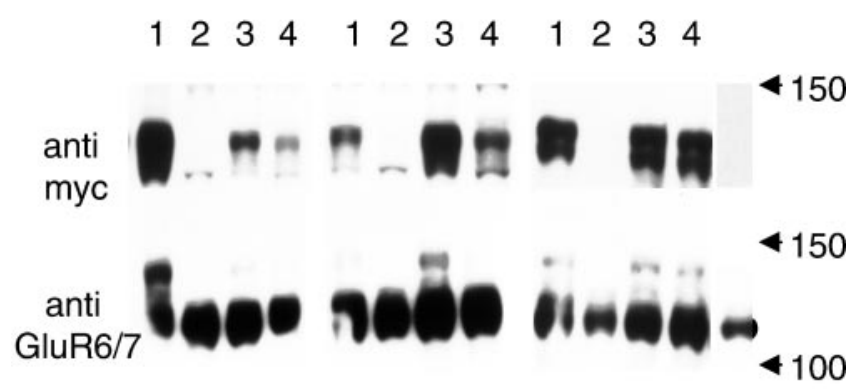

\section{1: cortex; 2: cerebellum; 3: hippocampus; 4: striatum}

Figure 1. Characterization of myc-GluR6 cDNA and transgenic mice. $A$ Functional expression of myc-GluR6 in HEK-293 cells. Cells were transiently transfected with myc-GluR6 cDNA. Whole-cell currents recorded in response to application of kainate $(20 \mu \mathrm{M})$ in the presence of Con A are shown. Holding current, $-70 \mathrm{mV}$. $B$, Surface expression of myc-GluR6 transiently transfected in COS-7 cells and cultured hippocampal neurons revealed with an anti-myc antibody. $C$, Schematic drawing of myc-GluR6 transgene construct. $D$, Expression of myc-GluR6 in selected brain regions for three transgenic mice families. Brain membrane extracts $(15 \mu \mathrm{g})$ were analyzed in immunoblots probed with anti-myc (top) or antiGluR6/7 (bottom) antibodies. Myc-GluR6 is differentially expressed in forebrain regions (hippocampus, striatum, and neocortex), but no expression is detected in the cerebellum. In wild-type mice (WT; right lane), no band is detected with the anti-myc antibody. Arrows indicate molecular weight markers.

herin/catenin complex using immunoprecipitation experiments on solubilized brain membranes. Antibodies available for GluR6containing KARs are directed against the intracellular $\mathrm{C}$ terminal of the protein, raising the possibility that interaction of the antibody with its epitope disrupts interaction of GluR6 with intracellular partners. To circumvent this difficulty, we have produced transgenic mice expressing the GluR6 subunit with an epitope tag at its extracellular N-terminal domain.

We have inserted six myc epitopes within the GluR6 $\mathrm{N}$-terminal sequence after the signal peptide (myc-GluR6). We have first checked that myc-GluR6 was functional by heterologous expression in HEK-293 cells (Fig. 1A). In electrophysiolog- ical experiments, application of kainate $(20 \mu \mathrm{M})$ in the presence of Con A to cells transfected with myc-GluR6 consistently evoked an inward current. We then verified that the placement of the epitope tag in the extracellular domain made it available for antibody staining under living conditions. In transfected COS-7 cells and rat hippocampal neurons in primary cultures, anti-myc antibodies labeled surface-expressed myc-GluR6 receptors, which appeared as puncta (Fig. $1 B$ ). We then generated transgenic mice expressing myc-GluR6 subunit under the control of the promoter of the CaMKII $\alpha$ (Fig. 1C). This promoter has been widely used because it confers specific expression of the transgene in postnatal forebrain neurons (Mayford et al., 1996) and is of great interest for our study because a large proportion of forebrain neurons in the striatum, the neocortex, or the hippocampus endogenously express the GluR6 subunit (Wisden and Seeburg, 1993; Bischoff et al., 1997). In six transgenic mouse lines, the myc-GluR6 protein was detected by Western blotting with an anti-myc antibody in brain extracts from the neocortex, the striatum, and the hippocampus (Fig. 1D). Myc-GluR6 was not detected in the cerebellum, another brain region in which the endogenous GluR6 subunit is highly expressed, confirming the forebrain-specific expression of the transgene under the control of the $\mathrm{CaMKII} \alpha$ promoter. Differing genomic integration positions generated mouse lines with a variable pattern of expression of the transgene, as illustrated in Figure $1 D$. In some mouse lines, myc-GluR6 was evenly expressed in the hippocampus, the neocortex, and the striatum (for instance, transgenic line 28), whereas in others, myc-GluR6 was more abundant in a particular brain region (neocortex for line 23, hippocampus for line 26). The relative amount of myc-GluR6 compared with endogenous GluR6 could be evaluated by taking advantage of the difference in molecular weight between the two proteins, because of the presence of the six myc fragments $(11 \mathrm{kDa})$ (Fig. 1D). Myc-GluR6 represents $\sim 10-20 \%$ of the endogenous protein. The following experiments were performed on line 28 .

\section{Association of transgenic myc-GluR6 with endogenous subunits and rescue of GluR6-null mutation in hippocampal CA3 pyramidal neuron}

KARs are heteromeric proteins with a tetrameric stoichiometry. GluR6 and KA2 subunits can associate to form native KARs in neurons. Thus, we examined whether the transgenic myc-GluR6 subunit combined in vivo with the endogenous GluR6 and KA2 subunits (Wenthold et al., 1994). KARs were immunoprecipitated from transgenic mouse brain extracts with either an antimyc, anti-GluR6/7, or anti-KA2 antibody and were probed with the antibodies specific for each subunit (Fig. $2 A$ ). No signal was detected in control immunoprecipitation experiments from wildtype mouse brain extracts using an anti-myc antibody or from transgenic mouse brain extracts using an unrelated antibody. The totality of receptors was solubilized and immunoprecipitated with each of the antibodies (data not shown). In transgenic mice, GluR6 and KA2 subunits were immunoprecipitated with the anti-myc antibody, and myc-GluR6 was immunoprecipitated with the anti-GluR6/7 or the anti-KA2 antibody. This result indicates that the transgenic myc-GluR6 subunit participates in the heteromeric assembly of native KARs. It also shows that myc-GluR6 is, at least in part, expressed in neurons that endogenously express GluR6 and KA2. Finally, the AMPAR subunit GluR2 does not coimmunoprecipitate with myc-GluR6, indicating that these two types of receptors do not take part in the same glutamate receptor complex (Fig. 2B). In additional experiments, we also find that 


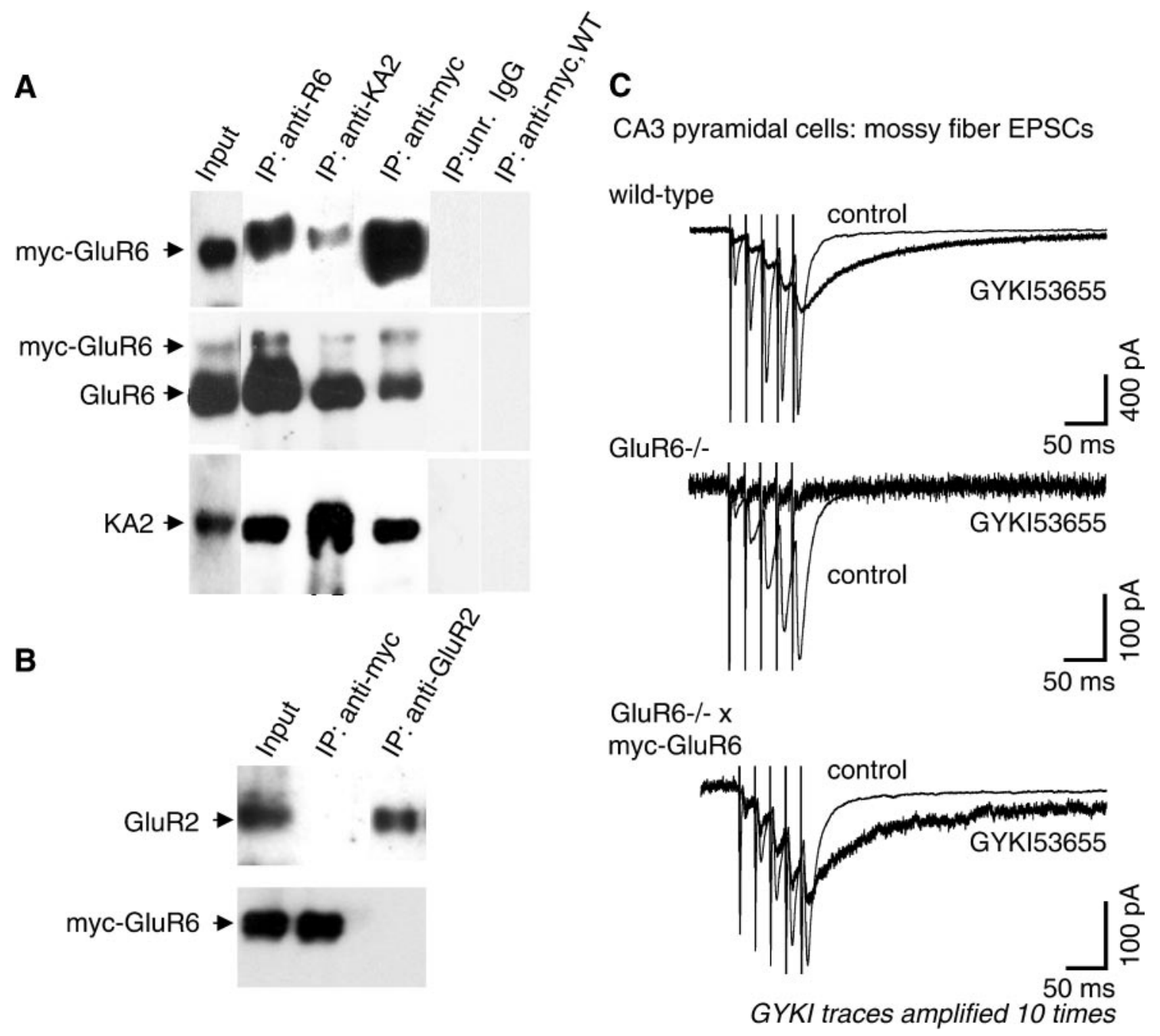

Figure 2. Myc-GluR6 is associated with endogenous KAR subunits. A, Coimmunoprecipitation of myc-GluR6 with endogenous GluR6 and KA2 subunits. Triton X-100 brain extracts from transgenic mice were immunoprecipitated (IP) with anti-myc, anti-GluR6, or anti-KA2 antibodies. Immunoblot analysis was performed with the three antibodies. Control experiments (right lanes): immunoprecipitation of transgenic mouse brain extracts with an unrelated IgG (anti-GST antibody); immunoprecipitation of wild-type (WT) mouse brain extracts with an anti-myc antibody. $B$, Myc-GluR6 is not associated with GluR2 AMPA receptor subunit. Triton X-100 brain extracts from transgenic mice were immunoprecipitated with anti-myc or anti-GluR2 antibodies, and both proteins were analyzed by Western blot. $C$, Rescue of KAR-mediated synaptic currents in GluR6 ${ }^{-1-}$ mice by the myc-GluR6 transgene. Whole-cell patch-clamp recordings of CA3 pyramidal cells in hippocampal slices in the presence of antagonists of GABA and NMDA receptors (10 $\mu \mathrm{M}$ bicuculline and $25 \mu \mathrm{M}$ D-AP-5) are shown. Synaptic currents were evoked by a train of stimulations to mossy fibers. Blockade of AMPA receptors by the noncompetitive antagonist GYKI53655 revealed a slow synaptic component of small amplitude mediated by GluR6-containing KARs. The trace in the presence of GYKI was amplified 10-fold. The slow synaptic currents are not detected in GluR6 ${ }^{-1-}$ mice and are rescued in GluR6 $^{-1-}$ mice mated with myc-GluR6 transgenic mice. Holding current, $-70 \mathrm{mV}$. Calibration: $50 \mathrm{msec}, 100 \mathrm{pA}$ (except for wild type, $400 \mathrm{pA}$ ).

neither NR1 nor GluR1 are immunoprecipitated from transgenic mouse brain extracts with the anti-myc antibody (data not shown).

We subsequently tested whether myc-GluR6-containing receptors were functional and properly inserted in the synaptic membrane of neurons in transgenic mice. For this purpose, we mated CaMKII $\alpha$-myc-GluR6 transgenic mice with GluR6-deficient mice (Mulle et al., 1998). The best described example of KARs activated by synaptic release of glutamate is the mossy fiber to CA3 pyramidal cell synapse (Castillo et al., 1997; Vignes and Collingridge, 1997). In hippocampal slices taken from wild-type mice, single and repetitive stimulations of mossy fibers evoke glutamatergic synaptic currents largely mediated by AMPARs in CA3 pyramidal neurons. In the presence of GYKI53655, a selective AMPAR antagonist, synaptic currents of small amplitude and slow kinetics are observed (Fig. 2C). These synaptic currents are blocked by CNQX, a nonselective antagonist of AMPARs and KARs, and are abolished in GluR6 ${ }^{-1-}$ mice (Fig. 2C) (Mulle et al., 1998), indicating that they are mediated by GluR6containing KARs. Expression of the myc-GluR6 transgene in GluR6 $^{-1-}$ mice restores KAR-mediated synaptic currents in CA3 pyramidal cells (Fig. 2C). We measured the amplitude of KAR-EPSCs in response to a train of five stimulations as a percentage of the amplitude of AMPA EPSCs for the same stimulations. The relative amplitude was $7.5 \pm 1.5 \%(n=8)$ for wild-type mice and $3.5 \pm 1.5 \%(n=4)$ for GluR6 ${ }^{-1-} \times$ CaMKII $\alpha$-myc-GluR6 mice. Expression of the myc-GluR6 transgene also rescues inward currents activated by bath application of kainate in the presence of GYKI53655 in CA3 pyramidal cells, in CA1 pyramidal cells, and in striatal neurons (data not shown). These data demonstrate that the transgenic myc-GluR6 subunit can functionally complement for the GluR6-null mutation. To- 


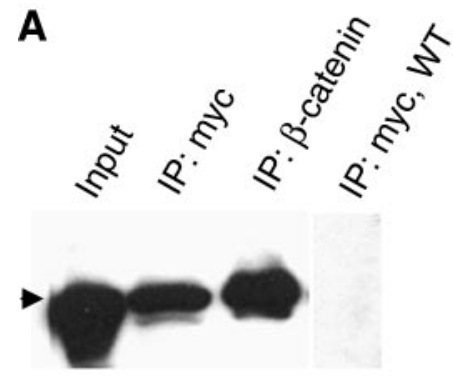

IB: $\beta$-catenin

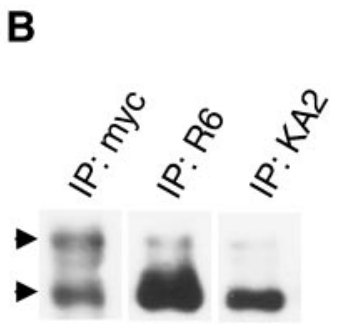

IB: GluR6

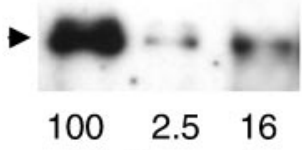

IB: $\beta$-catenin



IB: GluR6

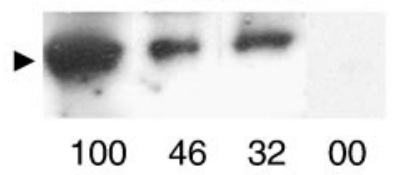

IB: $\beta$-catenin

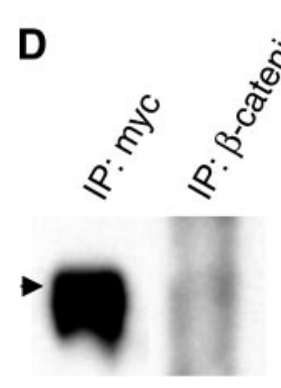

IB: myc

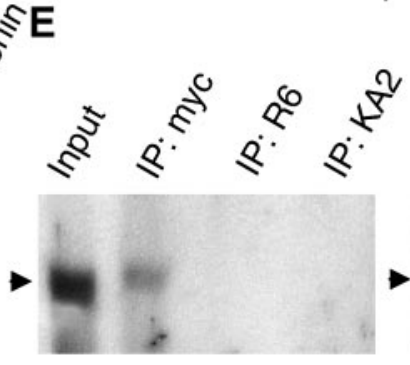

IB: p120

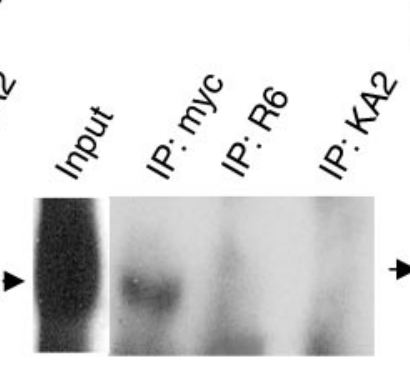

IB: pan cadherin
$F$

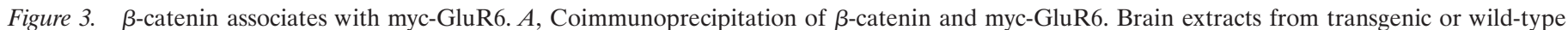

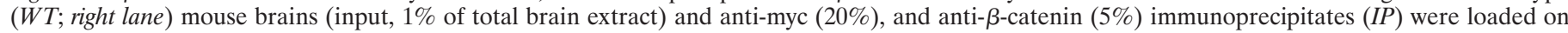



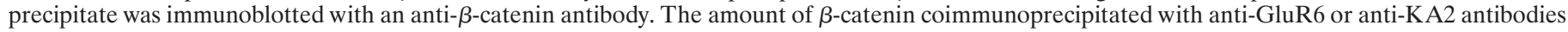

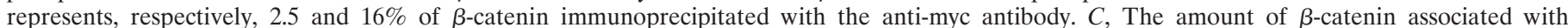



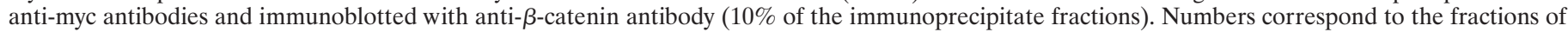

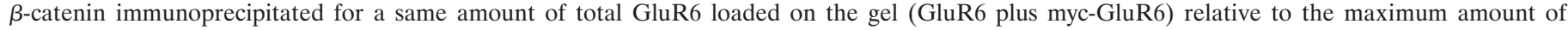



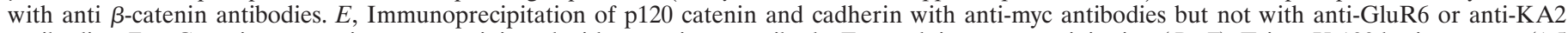

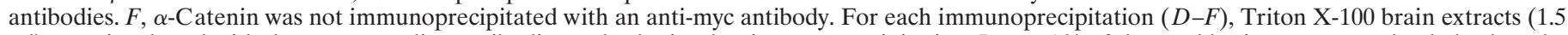

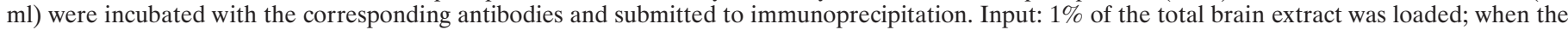

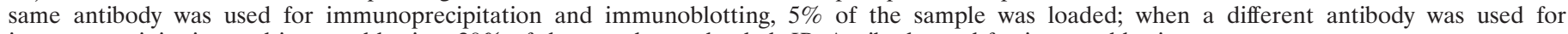
immunoprecipitation and immunoblotting, $20 \%$ of the sample was loaded. IB, Antibody used for immunoblotting.

gether, CaMKII $\alpha$-myc-GluR6 mice provide a good experimental model in the search of proteins associated with GluR6.

\section{GluR6 interacts with proteins of the cadherin/catenin complex}

We considered the possibility that KARs interact with proteins of the cadherin/catenin complex, which are known to be specifically expressed at the periphery of the postsynaptic density (Uchida et al., 1996), where KARs could be hypothetically localized. We first attempted to directly examine the subcellular localization of the myc-GluR6 protein, but the anti-myc antibody did not appear suitable for immunogold electron microscopy localization. We have thus used a biochemical approach to test for an interaction of GluR6 with proteins of the cadherin/catenin complex. Cadherins form a large family of adhesion proteins with highly variable expression depending on the type of synapses (Shapiro and Colman, 1999), but all classical cadherins directly bind to $\beta$-catenin (Jou et al., 1995). The anti-myc precipitate of transgenic brain extracts was probed with antibodies directed at proteins of the cadherin/catenin complex (Fig. 3). We found that a large fraction of $\beta$-catenin coimmunoprecipitated with myc-GluR6 (Fig. $3 A$ ) in all mouse lines tested. Interestingly, the amount of $\beta$-catenin coimmunoprecipitated with anti-GluR6/7 was only $2.5 \pm 0.2 \%(n=3)$ of the amount immunoprecipitated with anti-myc (Fig. 3B). A possible explanation for this difference is that the anti-GluR6/7 antibody is directed against the last 14 aa and can thus interfere with GluR6/ $\beta$-catenin interaction. The amount of $\beta$-catenin immunoprecipitated with anti-KA2 was significantly higher $(16 \pm 4 \%$ of the amount immunoprecipitated with anti-myc; $n=3$ ). The relative amount of $\beta$-catenin immunoprecipitated with the anti-myc antibody for an equivalent sample of proteins was variable depending on the different brain regions examined (Fig. $3 C$ ). The amount of $\beta$-catenin immunoprecipitated from the cortex and from the striatum was $46 \pm 3$ and $32 \pm 5 \%$, respectively $(n=4)$, compared with the amount immunoprecipitated from the hippocampus for the same amount of total GluR6 (GluR6 plus myc-GluR6) loaded on the gel. The transgenic protein myc-GluR6 was immunoprecipitated with an anti- $\beta$-catenin antibody, however, with low efficiency (Fig. $3 D$ ). The reason for this low efficiency may be linked to the fact that $\beta$-catenin/myc-GluR6 interaction only represents a small fraction $(7 \pm 1 \% ; n=6)$ of the interactions between $\beta$-catenin and other brain protein complexes. p120 catenin and cadherins were also 
immunoprecipitated with the anti-myc antibody, but we were unable to detect these proteins using anti-GluR6/7 or anti-KA2 antibodies (Fig. $3 E$ ). In contrast, no $\alpha$-catenin could be detected in the anti-myc immunoprecipitate (Fig. $3 F$ ), whereas $\alpha$-catenin takes part in the cadherin/catenin complex (Fig. $3 F$ ). To further document a possible interaction of $\beta$-catenin with GluR6 in neurons, we also transfected cultured hippocampal neurons with myc-GluR6 and compared the relative distribution of GluR6containing KARs with endogenous $\beta$-catenin. $\mathrm{N}$-cadherin and $\beta$-catenin cluster at synapses between neurons in culture (Benson and Tanaka, 1998). We found that $24 \mathrm{hr}$ after transfection, mycGluR6 was present as puncta partly colocalized with $\beta$-catenin and with the synaptic protein synaptophysin (Fig. 4).

\section{GluR6 interacts with Velis/LIN-7 and CASK/LIN-2 complexes}

CASK/LIN-2 is a member of the membrane-associated guanylate kinase (MAGUK) family concentrated at synapses and binds to neurexin and syndecan (Hata et al., 1996). It is a member of a tripartite cytoplasmic complex also composed of Mint/LIN-10 and Velis/LIN-7 (Butz et al., 1998), which associates with adhesion molecules as well as with receptors (Jo et al., 1999) and transporters for neurotransmitters (Perego et al., 1999). Velis/ LIN-7 proteins form a complex with cadherin and $\beta$-catenin in epithelia and neurons (Perego et al., 2000). This association relocates Velis/LIN-7 to $\beta$-catenin- containing junctional domains. Thus, we considered the possibility that GluR6 also interacts with proteins of this complex. As reported previously (Perego et al., 2000), we found that Velis, CASK, and $\beta$-catenin coimmunoprecipitated from mouse brain extracts (Fig. $5 A$ ). In transgenic mouse brain extracts, the anti-myc antibody immunoprecipitated Velis (Fig. 5B) and CASK (Fig. 5C). Conversely, myc-GluR6 was immunoprecipitated by an anti-Veli and an anti-CASK antibody (Fig. 5D). Control immunoprecipitation experiments from wildtype mouse brain extracts using an anti-myc antibody or from transgenic mouse brain extracts using an unrelated antibody gave no signal. These experiments indicate that GluR6 can take part in a large protein complex linking the cadherin/ $\beta$-catenin adhesion complex with the cytoplasmic CASK/Velis/Mint complex.

\section{The last amino acids of GluR6 are necessary for the interaction with $\boldsymbol{\beta}$-catenin and CASK}

To obtain more direct evidence for an interaction between GluR6, $\beta$-catenin, and CASK and to define by which protein domain of GluR6 these interactions occur, we have generated GST fusion proteins representing the entire intracellular C-terminal domain of GluR6 (R6Ctotal) or C-terminal domains truncated of $4(\mathrm{R} 6 \mathrm{C} \Delta 4)$ and $14(\mathrm{R} 6 \mathrm{C} \Delta 14)$ aa. Triton X-100 solubilized extracts from mouse brains were incubated with each of the GST-R6Cterm fusion proteins immobilized on beads. After extensive washing, the beads were immunoblotted for the presence of $\beta$-catenin, CASK, or PSD-95. As already reported, the full C-terminal domain of GluR6 binds to PSD-95 by an interaction with the last 4 aa (ETMA) (Garcia et al., 1998) (Fig. $6 A$ ). Identical results were obtained with CASK, which strongly binds to the last 4 aa of GluR6 (Fig. $6 B$ ). The last 4 aa of the $\mathrm{C}$-terminal domain are also involved in the interaction of $\beta$-catenin with GluR6 (Fig. $6 C$ ). A low-intensity band is still observed with the R6C $\Delta 4$ construct. No binding is detected with the R6C $\Delta 14$ construct or with GST alone for any of the proteins tested. The residual binding of $\beta$-catenin to $\mathrm{R} 6 \mathrm{C} \Delta 4$ construct underlines a difference in the mechanism of interaction of
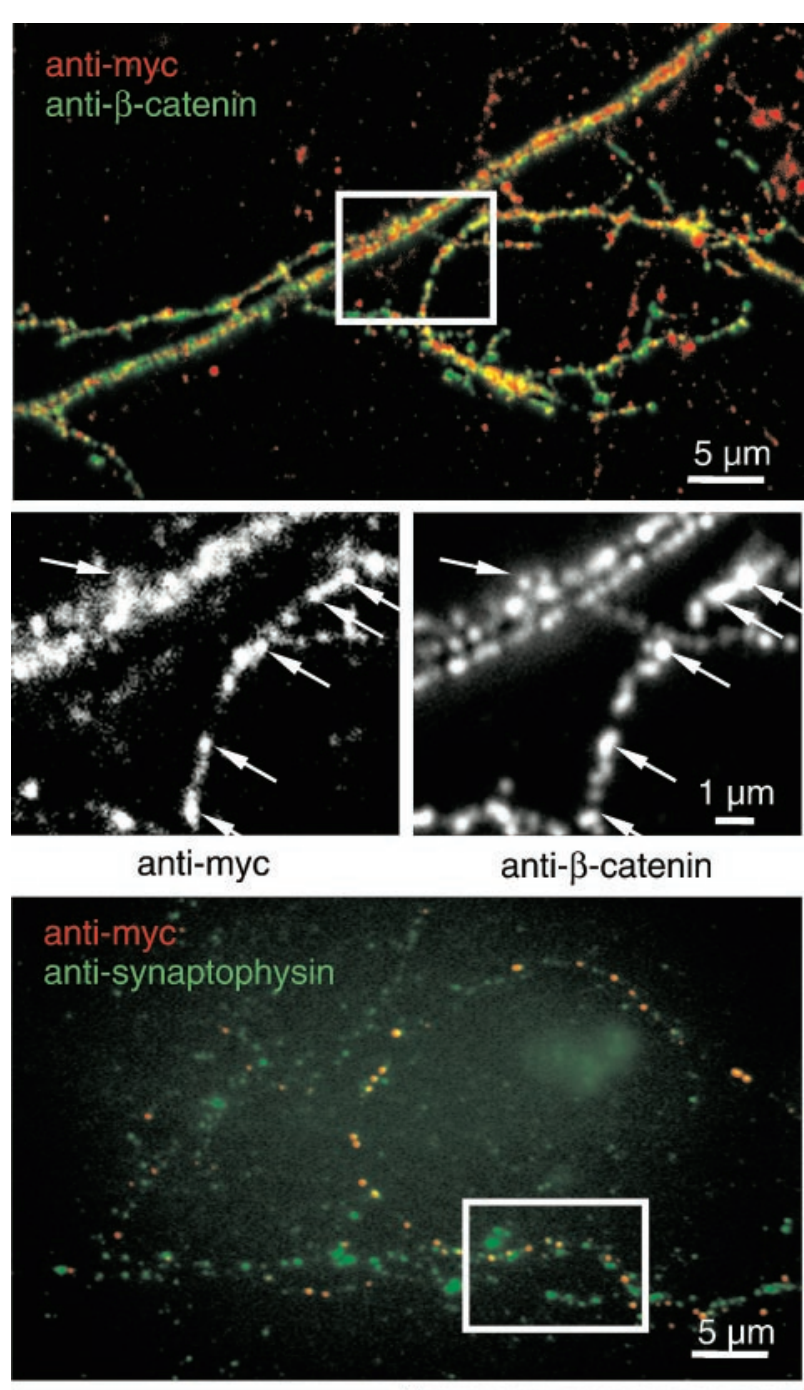



anti-myc

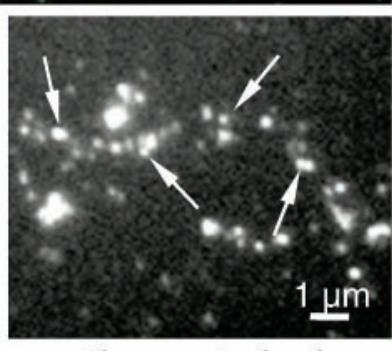

anti-synaptophysin
Figure 4. Myc-GluR6 colocalizes with endogenous $\beta$-catenin and synaptophysin in transfected hippocampal neurons. Myc-GluR6 was transfected in cultured hippocampal neurons at $12 \mathrm{~d}$ in vitro. One day later, neurons were labeled in vivo $\left(20 \mathrm{~min}\right.$ at $\left.20^{\circ} \mathrm{C}\right)$ with an anti-myc antibody, fixed, permeabilized, and then labeled for $\beta$-catenin (top panels) or synaptophysin (bottom panels). Labeling for anti-myc antibody is shown in red, and labeling for anti- $\beta$-catenin or anti-synaptophysin antibodies is shown in green. Arrows indicate colocalization between the two proteins. Scale bars are indicated. The boxed areas from the top panels are enlarged at the bottom of the figures.

$\beta$-catenin to the cytoplasmic domain of GluR6, compared with PSD-95 or CASK. Finally, there is no homophilic interaction between GluR6 C-terminal domains (Fig. 6D). We subsequently tested whether the interaction of $\beta$-catenin with the cytoplasmic domain of GluR6 was a direct interaction using $E$. coli-expressed 


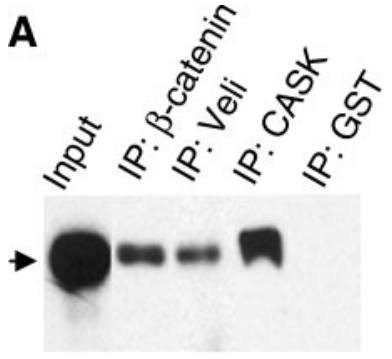

IB: CASK



IB: CASK

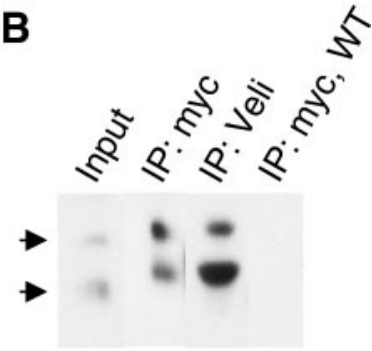

IB: Veli

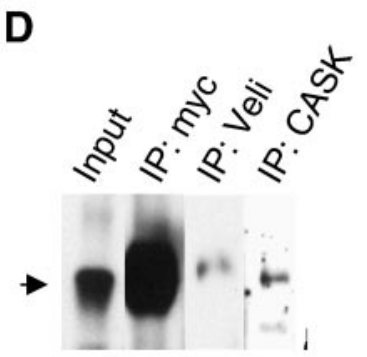

IB: myc
Figure 5. CASK and Velis associate with myc-GluR6. $A$, Coimmunoprecipitation of CASK with $\beta$-catenin and Velis. Triton X-100 brain extracts $(1.5 \mathrm{ml})$ were incubated with the corresponding antibodies, and $20 \%$ of the immunoprecipitate $(I P)$ samples were immunoblotted with an antiCASK antibody. Right lane, Control experiment using an unrelated IgG (anti-GST antibody). B, Coimmunoprecipitation of Velis and myc-GluR6. $C$, Coimmunoprecipitation of CASK and myc-GluR6. D, Coimmunoprecipitation of myc-GluR6 by anti-Veli and anti-CASK antibodies. $B-D$, In the input lane, $1 \%$ of the total brain extract was loaded; when the same antibody was used for immunoprecipitation and immunoblotting, $5 \%$ of the sample was loaded; when a different antibody was used for immunoprecipitation and immunoblotting, $25 \%$ of the sample was loaded. $B, C$, Right lane corresponds to a control immunoprecipitation on wild-type $(W T)$ brain extracts using an anti-myc antibody. $I B$, Antibody used for immunoblotting.

$\beta$-catenin in GST-pulldown experiments (Fig. 6E). In these experiments, $\beta$-catenin directly binds to the cytoplasmic domain of $\mathrm{N}$-cadherin but does not bind to the cytoplasmic domain of GluR6. In control experiments, PDZ domains 1 and 2 of PSD-95 directly bind to the C-terminal domain of GluR6, as reported previously (Garcia et al., 1998).

\section{Interactions of GluR6 with $\beta$-catenin in a non-neuronal cell line}

In neurons, multiple synaptic proteins, such as PSD-95 or CASK, might provide a link between GluR6 and the cadherin/catenin complex. If neuron-specific proteins are necessary links for an interaction between GluR6 and the cadherin/catenin adhesion complex, this interaction should not be observed in non-neuronal cells. Thus, we examined whether $\beta$-catenin, a ubiquitous protein expressed in most cell types, interacted with recombinant GluR6 expressed in non-neuronal cell lines. COS-7 cells were transfected with myc-GluR6 or myc-GluR6 614 cDNA, and detergentsolubilized membrane was immunoprecipitated with an anti-myc antibody and immunoblotted for $\beta$-catenin (Fig. 7A). We found that endogenous $\beta$-catenin interacts with GluR6 in COS-7 cells (Fig. 7A). These cells lack detectable amounts of PSD-95 or CASK (data not shown), indicating that interaction of GluR6 with $\beta$-catenin is not indirectly mediated by binding to PSD-95 or to CASK. As already reported in COS-7 cells transfected with PSD-95, GluR6 binds to PSD-95 (Garcia et al., 1998) (Fig. 7A).

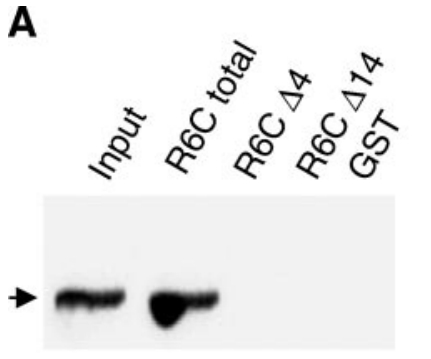

IB: PSD-95

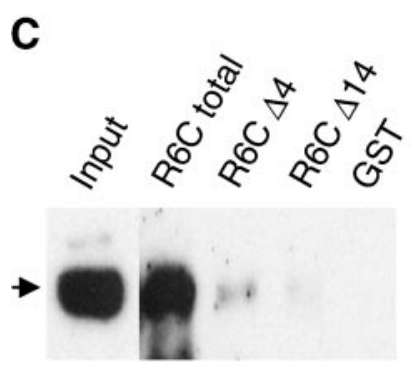

IB: $\beta$-catenin

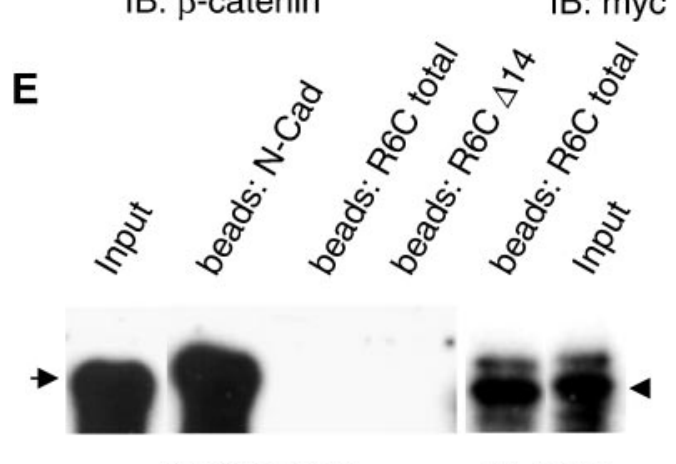

IB: $\beta$-catenin



IB: GST

IB: PSD

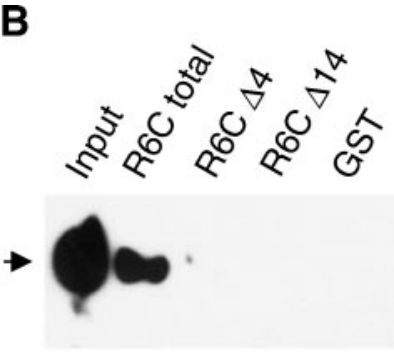

IB: CASK



IB: myc
C-terminal domain of GluR6 is necessary for $\beta$-catenin an CASK binding. $A-C$, GST-pulldown of PSD-95, CASK, and $\beta$-catenin. Brain supernatant was submitted for binding to GST and GST proteins fused to total GluR6 C terminal (R6Ctotal) and to GluR6 deleted of the last $4(\mathrm{R} 6 \mathrm{C} \Delta 4)$ or $14(\mathrm{R} 6 \mathrm{C} \Delta 14)$ aa. Twenty percent of the samples were immunoblotted and probed for PSD-95 $(A)$, CASK $(B), \beta$-catenin $(C)$, and myc-GluR6 $(D)$. $E$, Indirect binding of $\beta$-catenin to the $C$-terminal domain of GluR6. $\beta$-catenin expressed in bacteria was submitted for binding to the GST-cytoplasmic domain of N-cadherin ( $\mathrm{N}$-Cad), GSTGluR6 total C terminal, and GST-GluR6 14 . As a control, PSD-95 (PDZ domain 1-2) expressed in bacteria was submitted for binding to GSTGluR6 total C terminal. SDS gels were submitted for blotting with GST, $\beta$-catenin, or PSD-family antibodies as indicated. $I B$, Antibody used for immunoblotting.

PSD-95 and $\beta$-catenin are not immunoprecipitated in COS-7 cells transfected with a mutant form of GluR6 lacking the last 14 aa (GluR6 14). Interestingly, overexpression of PSD-95 results in a decrease in the amount of $\beta$-catenin bound to myc-GluR6 (by a factor of $3 ; n=4)$. This result is consistent with the finding that $\beta$-catenin and PSD-95 bind to the same site on the GluR6 subunit. 

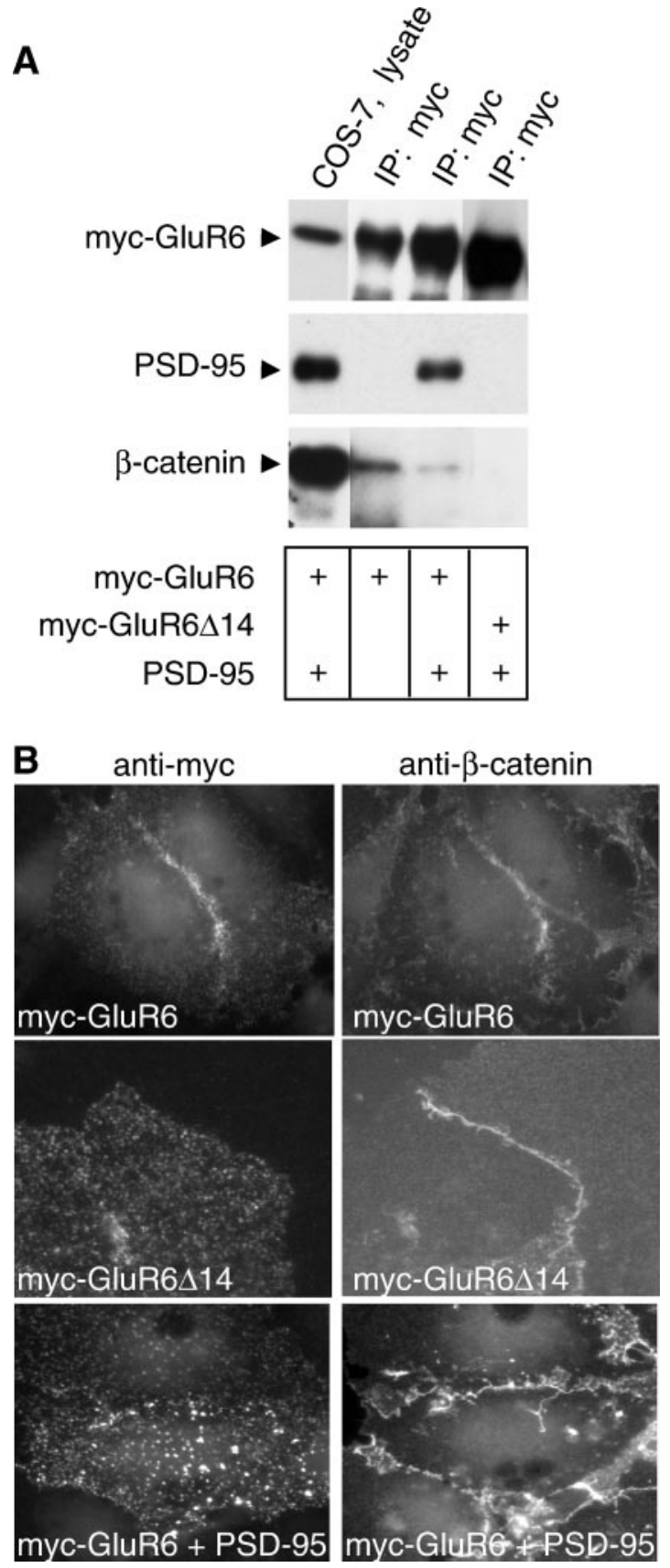

Figure 7. Endogenous $\beta$-catenin coimmunoprecipitates and colocalizes with myc-GluR6 in transfected COS-7 cells. Myc-GluR6 or mycGluR6 14 were transfected with or without PSD-95 in COS-7 cells. After $1 \mathrm{~d}$, cells were extracted, and Triton X-100 supernatants were immunoprecipitated with an anti-myc antibody. $A$, Immunoprecipitates $(I P)$ were immunoblotted with anti-myc, anti-PSD-95, or anti- $\beta$-catenin antibodies. Endogenous $\beta$-catenin coimmunoprecipitates with myc-GluR6 in transfected COS-7 cells. $B$, Immunocytochemistry of COS-7 cells transfected with myc-GluR6, myc-GluR6 $\Delta 14$, or myc-GluR6 plus PSD-95 with an anti-myc antibody (surface labeling) and an anti- $\beta$-catenin antibody (intracellular labeling). Myc-GluR6, but not myc-GluR6 $\Delta 14$, colocalizes with $\beta$-catenin at cell-cell junctions. Expression of PSD-95 decreases localization of myc-GluR6 at the junction of the cells.

It also suggests a possible competition between PSD-95 and $\beta$-catenin for an interaction with GluR6, which can be relevant to the distribution of GluR6 in distinct synaptic membrane subdomains. We subsequently compared the subcellular localization of $\beta$-catenin and myc-GluR6 in COS-7 cells. Immunofluorescent staining of myc-GluR6 in live COS-7 cells indicates that GluR6 receptors are concentrated at the edge of the cell, in cell-cell membrane junctions (Fig. 7B). The distribution of GluR6 largely overlaps the distribution of endogenous $\beta$-catenin in these cellular domains. The coexpression of PSD-95 with myc-GluR6 in COS-7 cells decreases the localization of GluR6 at cell-cell junctions (Fig. 7B). GluR6 14 transfected in COS-7 cells can also be detected using the extracellular anti-myc antibody on live cells (Fig. $7 B$ ), indicating that the lack of interaction with PSD-95 or $\beta$-catenin is not caused by a mistargeting of GluR6 $\Delta 14$ to the plasma membrane. At variance with full-length GluR6, GluR6 $\Delta 14$ is uniformly distributed at the cell surface and does not overlap with $\beta$-catenin at cell-cell junctions.

\section{Redistribution of GluR6 follows reorganization of cadherin/catenin complex in conditions mimicking cadherin-mediated cell contact formation}

During establishment of cell-cell contacts, for instance during synapse formation and maturation, a complex regulation of cadherin-mediated adhesion occurs, leading to the remodeling of cadherin-cadherin and cadherin-cytoskeleton interaction. A model was developed to mimic and control the formation of cadherin-mediated cell-cell contacts (Lambert et al., 2000). In this model, latex beads covered with the extracellular domain of $\mathrm{N}$-cadherin bind to cells expressing $\mathrm{N}$-cadherin and induce the recruitment of $\mathrm{N}$-cadherin, $\beta$-catenin, $\alpha$-catenin, and $\mathrm{p} 120$ catenin under the beads, as well as the reorganization of the cytoskeleton. Thus, we examined whether activation of the cadherin/catenin complex induced a reorganization of GluR6. Recombinant chimeric protein Ncad-Fc comprising the chicken N-cadherin extracellular domain fused to the Fc fragment of the mouse IgG2b was produced and purified from HEK-293 cells and was immobilized on $6 \mu \mathrm{m}$ latex beads (Lambert et al., 2000). These beads bind in a $\mathrm{Ca}^{2+}$-dependent manner to $\mathrm{N}$-cadherin-expressing cells, such as C2 mouse myogenic cells. We transfected C2 cells with mycGluR6 or with myc-GluR6 14 . As in COS-7 cells, both receptors were expressed at the cell surface, as evidenced by live antibody staining, followed by immunofluorescent detection, and mycGluR6 was found to be highly concentrated at cell-cell contacts (data not shown). Beads coated with an anti-myc antibody or with the Ncad-Fc protein were allowed to bind to myc-GluR6transfected $\mathrm{C} 2$ cells. As already reported, strong accumulations of $\mathrm{N}$-cadherin and $\beta$-catenin were detected at the sites of contact between the coated beads and the cell surface (Lambert et al., 2000). We found that activation of the cadherin/catenin complex by the $\mathrm{N}$-cadherin-coated beads resulted in a strong accumulation of myc-GluR6 at the sites of bead-C2 cell contact (Fig. 8A). This redistribution of myc-GluR6 was not observed in cells transfected with myc-GluR6 14 (Fig. 8B). Binding of anti-myc-coated beads to $\mathrm{C} 2$ cells induced antibody-mediated recruitment of myc-GluR6 (Fig. $8 C$ ) but did not result in the redistribution of N-cadherin and $\beta$-catenin (Fig. 8D). These results indicate that myc-GluR6 surface receptors redistribute after reorganization of the cadherin/catenin complex, mimicking the establishment of cell-cell contacts and suggesting an important role for cadherin $/ \beta$-catenin complexes in the stabilization of GluR6 KARs at the synaptic membrane.

\section{DISCUSSION}

In this study, we demonstrate that GluR6 interacts both in vivo and in vitro with the protein $\beta$-catenin, an intracellular partner of 
Immunostaining: myc-tag
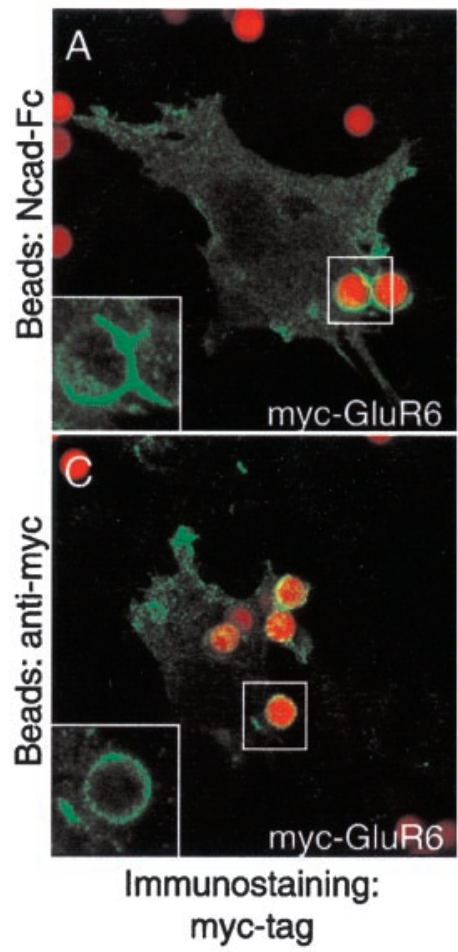

Immunostaining: myc-tag


Immunostaining: $\beta$-catenin
Figure 8. Myc-GluR6 redistribution follows the distribution of $\beta$-catenin. C2 cells were transfected with myc-GluR6 $(A, C, D)$ or mycGluR6 $\Delta 14(B)$. Twenty-four hours later, Ncad-Fc- $(A, B)$ or anti-myc- $(C$, $D$ ) coated beads were incubated with cells for $45 \mathrm{~min}$. Cells were fixed, permeabilized, and probed with anti-myc tag or anti- $\beta$-catenin antibodies. Activation of cadherin induces recruitment of myc-GluR6 under the bead $(A)$. There is no recruitment of myc-GluR $6 \Delta 14$ by Ncad-Fc-coated beads $(B)$. Anti-myc antibody-coated beads induce a strong recruitment of myc-GluR6 at the bead-cell contact $(C)$. However, recruitment of mycGluR6 is not followed by recruitment of $\beta$-catenin under the beads $(D)$.

all classical cadherins, as well as with CASK, a PDZ domain protein. In an experimental model mimicking establishment of cell-cell contacts, we show that activation of N-cadherins induces a redistribution of GluR6, which parallels the reorganization of the cadherin/catenin complex.

In contrast to AMPA and NMDA receptors, little is known about proteins that interact with KAR subunits and how KARs are addressed and stabilized in the synaptic membrane. As a first step in understanding these mechanisms, we have generated transgenic mice expressing an epitope-tagged GluR6 subunit under the control of the CaMKII $\alpha$ subunit promoter. This promoter was chosen because it is known to drive expression of the transgene to postnatal forebrain neurons (Mayford et al., 1996). The GluR6 subunit is expressed at a high level in various forebrain neurons and in the neocortex, the striatum, and the hippocampus (Wisden and Seeburg, 1993; Bischoff et al., 1997; Bureau et al., 1999). A comparative analysis of wild type and GluR6 $^{-1-}$ has demonstrated the presence of presynaptic and postsynaptic GluR6-containing KARs in these brain areas (Mulle et al., 1998, 2000; Bureau et al., 1999; Chergui et al., 2000; Contractor et al., 2000). We have obtained mouse lines with different patterns of expression of the myc-GluR6 transgene in the neocortex, the striatum, and the hippocampus. Immunocytochemical experiments to detect the subcellular localization of
myc-GluR6 using an anti-myc antibody have been unsuccessful. However, in search of proteins interacting with GluR6, we have performed coimmunoprecipitation experiments, taking advantage of the myc epitope inserted at the extracellular N-terminal end of the GluR6 subunit. In previous studies, anti-GluR6/7 antibodies used were directed to the C-terminal domain of GluR6 (Garcia et al., 1998). We reasoned that such antibodies might impede on protein-protein interactions with $\mathrm{C}$-terminal intracellular domains. We first verified that myc-GluR6 was functional and properly targeted in vivo. For this purpose, we have mated myc-GluR6 transgenic mice with GluR6 ${ }^{-/-}$mice and found that myc-GluR6 efficiently replaced the missing GluR6 subunit in the hippocampus: myc-GluR6 was properly inserted in the synaptic membrane of CA3 pyramidal cells, as judged by the recovery of KAR-mediated synaptic currents in CaMKII $\alpha$-myc-GluR6 $\times$ GluR6 $^{-1-}$ mice. In addition, immunoprecipitation experiments clearly indicate an association of myc-GluR6 with endogenous GluR6 and KA2 subunits, indicating that myc-GluR6 is present in neurons endogenously expressing GluR6 and KA2, and that it takes part in the heteromeric KAR combination. Finally, as already reported for endogenous GluR6-containing KARs, mycGluR6 interacts with PSD-95. We found, however, that the AMPAR subunit GluR2 and myc-GluR6 do not coimmunoprecipitate, indicating that AMPARs and KARs take part in distinct protein complexes, as already suggested by large-scale analysis of the NMDA receptor complex (Husi et al., 2000).

Electrophysiological analysis of KAR-mediated EPSCs has lent support to the hypothesis that KARs could be located in a perisynaptic subdomain (Bureau et al., 2000). In synaptic junctions, the cell-cell adhesion proteins cadherins, together with their intracellular partners catenins, are concentrated in an "adhesion belt" surrounding the synaptic active zone (Fannon and Colman, 1996; Uchida et al., 1996; Bruses, 2000), a region where synaptic KARs could be concentrated. Thus, we have explored whether GluR6 interacts with proteins of the cadherin/catenin complex. Coimmunoprecipitation experiments from transgenic mouse forebrains have demonstrated a strong interaction between myc-GluR6 and $\beta$-catenin. Myc-GluR6 also interacts with cadherins and p120 catenin, an intracellular partner of cadherins, but not with $\alpha$-catenin. Consistent with this result, $\mathrm{N}$-cadherin and $\beta$-catenin, but not $\alpha$-catenin, are present in large NMDAR multiprotein complexes, which are also immunopositive for GluR6/7 (Husi et al., 2000). Using the same anti-GluR6/7 antibody, which is directed at the intracellular C-terminal domain, $\beta$-catenin was hardly immunoprecipitated from mouse brain extracts. Thus, binding of GluR6/7 antibody to GluR6 C-terminal domain impedes interactions of GluR6 with $\beta$-catenin but not with PSD-95 (Garcia et al., 1998). CASK/LIN-2, a MAGUK protein concentrated at synapses (Hata et al., 1996), also coimmunoprecipitates with GluR6. CASK/LIN-2 takes part in a tripartite cytoplasmic complex, which might link cell-adhesion molecules to PSD proteins, such as PSD-95, and to receptors and transporters for neurotransmitters (Jo et al., 1999; Perego et al., 1999, 2000).

Experiments using purified proteins in GST-pulldown experiments show that the interaction of GluR6 with $\beta$-catenin is indirect. The link between GluR6 with $\beta$-catenin has not been identified. However, we provide several pieces of evidence suggesting that interaction of GluR6 with $\beta$-catenin is not mediated by its interaction with CASK or with PSD-95 and does not require complex interactions involving synapse-specific proteins. In GSTpulldown experiments using fusion proteins constructed with 
full-length or truncated GluR6 C-terminal domains, CASK and PSD-95 (Garcia et al., 1998) interact with full-length GluR6 C terminal but not with GluR6 $\Delta 4$, whereas some interaction is retained for $\beta$-catenin with the GluR6 44 construct. In addition, GluR6 and endogenous $\beta$-catenin interact in transfected COS-7 cells, which lack most proteins enriched in synaptic junctions, such as PSD-95 or CASK. Finally, cotransfection of PSD-95 with myc-GluR6 in COS-7 cells results in a decrease in $\beta$-catenin interaction with GluR6, whereas an increased binding would be expected if PSD-95 (or an analogous PDZ domain protein) provided a link between $\beta$-catenin and GluR6.

What insight do these experiments give as to the subcellular distribution of GluR6-containing KARs? Comparison of the distribution of GluR6 and $\beta$-catenin in the non-neuronal cells COS-7 and C2 demonstrates a striking overlap of the two proteins at cell-cell junctions. Enrichment of myc-GluR6 at cell-cell junctions is lost when the C-terminal domain is deleted of 14 aa, whereas this truncated form of GluR6 is properly inserted in the plasmic membrane. In neurons, cadherin/catenin proteins are enriched in regions forming an adhesion belt bordering transmitter release zones (Fannon and Colman, 1996; Uchida et al., 1996; Bruses, 2000). The localization of GluR6-containing KARs together with $\beta$-catenin at perisynaptic sites could provide an explanation for the unexpected properties of KAR-mediated EPSCs (for review, see Bureau et al., 2000; Frerking and Nicoll, 2000). Localization of KARs at some distance from glutamate release sites would account for a low concentration of glutamateactivating synaptic KARs, resulting in small amplitude, slow activation, and summation properties of KAR-EPSCs. It must be noted, however, that PSD-95, a protein enriched in the postsynaptic density, also interacts with GluR6. In COS-7 cells, PSD-95 and $\beta$-catenin appear to compete for the binding to GluR6. This competition might be relevant to the distribution of distinct pools of GluR6-containing KARs in distinct synaptic subdomains, either at the center of the postsynaptic density where PSD-95 is enriched or at regions bordering transmitter release zones colocalized with $\beta$-catenin proteins (Fannon and Colman, 1996; Uchida et al., 1996; Bruses, 2000). $\alpha$-Catenin, which binds $\beta$-catenin (Gumbiner, 1995), does not coimmunoprecipitate with myc-GluR6 from transgenic mouse brain extracts. Large-scale analysis of the NMDA receptor complex has also shown lack of interaction with $\alpha$-catenin (Husi et al., 2000). Cadherins are distributed symmetrically across the synaptic junction at presynaptic and postsynaptic sites and thus could associate with GluR6 in the postsynaptic membrane, as well as in axon terminals. For instance, at the mossy fiber-CA3 synapse, GluR6-containing KARs appear to be both presynaptic and postsynaptic (Mulle et al., 1998; Contractor et al., 2000). However, it is at present unclear whether presynaptic KARs are located on axon terminals or on axons at some distance from the synaptic terminal.

There is mounting evidence for an interplay between synaptic adhesion and synaptic plasticity (Tang et al., 1998; Bozdagi et al., 2000; Manabe et al., 2000). However, KARs are involved in different forms of synaptic plasticity, by acting at presynaptic or postsynaptic sites (Bortolotto et al., 1999; Contractor et al., 2001; Li et al., 2001). Cadherin-mediated synaptic adhesion is a dynamic process that could depend on the state of activity of the synapse (Tanaka et al., 2000). Changes in adhesivity that occur through development or during the formation of new synapses (Benson and Tanaka, 1998; Tanaka et al., 2000) may be an important mechanism by which synaptic properties are regulated. In experiments mimicking the formation of cadherin-mediated adhesive junctions using N-cadherin-covered beads, GluR6 tightly follows the redistribution of cadherin/catenin complexes, as well as the reorganization of the cytoskeleton induced by activation of $\mathrm{N}$-cadherins, such as what occurs during the formation and remodeling of synaptic junctions. However, enrichment of myc-GluR6 at contacts between anti-myc-covered latex beads and cell membrane does not result in a parallel enrichment of cadherin/catenin complexes. This implies that a large pool of GluR6 is not associated with cadherin/catenin proteins under basal conditions and that activation of cadherins promotes the recruitment of GluR6 to the cadherin/catenin complex. These results strongly suggest a role for cadherin/catenin proteins in targeting and/or stabilizing GluR6 at synaptic junctions. It is tempting to speculate that GluR6-mediated synaptic transmission, and consequently its implication in synaptic plasticity, will be controlled by dynamic changes in cadherin-mediated adhesive properties. Inversely, GluR6/cadherin interaction might provide a link between synaptic activation and cadherin/catenin-mediated intracellular processes. Together, our results open new perspectives for the understanding of the synaptic functions of cadherin/ catenin complexes.

\section{REFERENCES}

Benson DL, Tanaka H (1998) N-cadherin redistribution during synaptogenesis in hippocampal neurons. J Neurosci 18:6892-6904.

Bettler B, Mulle C (1995) AMPA and kainate receptors. Neuropharmacology 34:123-139.

Bischoff S, Barhanin J, Bettler B, Mulle C, Heinemann S (1997) Spatial distribution of kainate receptor subunit mRNA in the mouse basal ganglia and ventral mesencephalon. J Comp Neurol 379:541-562.

Bortolotto ZA, Clarke VR, Delany CM, Parry MC, Smolders I, Vignes M, Ho KH, Miu P, Brinton BT, Fantaske R, Ogden A, Gates M, Ornstein PL, Lodge D, Bleakman D, Collingridge GL (1999) Kainate receptors are involved in synaptic plasticity. Nature 402:297-301.

Bozdagi O, Shan W, Tanaka H, Benson DL, Huntley GW (2000) Increasing numbers of synaptic puncta during late-phase LTP: $\mathrm{N}$-cadherin is synthesized, recruited to synaptic sites, and required for potentiation. Neuron 28:245-259.

Bruses JL (2000) Cadherin-mediated adhesion at the interneuronal synapse. Curr Opin Cell Biol 12:593-597.

Bureau I, Bischoff S, Heinemann SF, Mulle C (1999) Kainate receptormediated responses in the CA1 field of wild-type and GluR6-deficient mice. J Neurosci 19:653-663.

Bureau I, Dieudonne S, Coussen F, Mulle C (2000) Kainate receptormediated synaptic currents in cerebellar golgi cells are not shaped by diffusion of glutamate. Proc Natl Acad Sci USA 97:6838-6843.

Butz S, Okamoto M, Sudhof TC (1998) A tripartite protein complex with the potential to couple synaptic vesicle exocytosis to cell adhesion in brain. Cell 94:773-782.

Castillo PE, Malenka RC, Nicoll RA (1997) Kainate receptors mediate a slow postsynaptic current in hippocampal CA3 neurons. Nature 388:182-186.

Chergui K, Bouron A, Normand E, Mulle C (2000) Functional GluR6 kainate receptors in the striatum: indirect downregulation of synaptic transmission. J Neurosci 20:2175-2182.

Chittajalu R, Braithwaite S, Clarke V, Henley J (1999) Kainate receptors: subunits, synaptic localization and function. Trends Pharmacol Sci 20:26-35

Contractor A, Swanson GT, Sailer A, O'Gorman S, Heinemann SF (2000) Identification of the kainate receptor subunits underlying modulation of excitatory synaptic transmission in the CA3 region of the hippocampus. J Neurosci 20:8269-8278.

Contractor A, Swanson G, Heinemann SF (2001) Kainate receptors are involved in short- and long-term plasticity at mossy fiber synapses in the hippocampus. Neuron 29:209-216.

Fannon AM, Colman DR (1996) A model for central synaptic junctional complex formation based on the differential adhesive specificities of the cadherins. Neuron 17:423-434.

Frerking M, Nicoll RA (2000) Synaptic kainate receptors. Curr Opin Neurobiol 10:342-351.

Garcia EP, Mehta S, Blair LA, Wells DG, Shang J, Fukushima T, Fallon JR, Garner CC, Marshall J (1998) SAP90 binds and clusters kainate receptors causing incomplete desensitization. Neuron 21:727-739.

Gumbiner BM (1995) Signal transduction of beta-catenin. Curr Opin Cell Biol 7:634-640.

Hata Y, Butz S, Sudhof TC (1996) CASK: a novel dlg/PSD95 homolog 
with an N-terminal calmodulin-dependent protein kinase domain identified by interaction with neurexins. J Neurosci 16:2488-2494.

Hemar A, Olivo JC, Williamson E, Saffrich R, Dotti CG (1997) Dendroaxonal transcytosis of transferrin in cultured hippocampal and sympathetic neurons. J Neurosci 17:9026-9034.

Husi H, Ward MA, Choudhary JS, Blackstock WP, Grant SG (2000) Proteomic analysis of NMDA receptor-adhesion protein signaling complexes. Nat Neurosci 3:661-669.

Jo K, Derin R, Li M, Bredt DS (1999) Characterization of MALS/ Velis-1, -2, and -3: a family of mammalian LIN-7 homologs enriched at brain synapses in association with the postsynaptic density-95/NMDA receptor postsynaptic complex. J Neurosci 19:4189-4199.

Jou TS, Stewart DB, Stappert J, Nelson WJ, Marrs JA (1995) Genetic and biochemical dissection of protein linkages in the cadherin-catenin complex. Proc Natl Acad Sci USA 92:5067-5071.

Lambert M, Padilla F, Mege RM (2000) Immobilized dimers of $\mathrm{N}$-cadherin-Fc chimera mimic cadherin-mediated cell contact formation: contribution of both outside-in and inside-out signals. J Cell Sci 113:2207-2219.

Lerma J, Paternain AV, Rodriguez-Moreno A, Lopez-Garcia JC (2001) Molecular physiology of kainate receptors. Physiol Rev 81:971-998.

Li H, Chen A, Xing G, Wei ML, Rogawski MA (2001) Kainate receptor-mediated heterosynaptic facilitation in the amygdala. Nat Neurosci 4:612-620.

Manabe T, Togashi H, Uchida N, Suzuki SC, Hayakawa Y, Yamamoto M, Yoda H, Miyakawa T, Takeichi M, Chisaka O (2000) Loss of cadherin-11 adhesion receptor enhances plastic changes in hippocampal synapses and modifies behavioral responses. Mol Cell Neurosci 15:534-546.

Mayford M, Baranes D, Podsypanina K, Kandel ER (1996) The 3'untranslated region of CaMKII alpha is a cis-acting signal for the localization and translation of mRNA in dendrites. Proc Natl Acad Sci USA 93:13250-13255.

Mehta S, Wu H, Garner CC, Marshall J (2001) Molecular mechanisms regulating the differential association of kainate receptor subunits with SAP90/PSD-95 and SAP97. J Biol Chem 276:16092-16099.

Mulle C, Andreas S, Pérez-Otaño I, Dickinson-Anson H, Castillo PE, Bureau I, Maron C, Gage FH, Mann JR, Bettler B, Heinemann SF (1998) Altered synaptic physiology and reduced susceptibility to kainate induced seizures in GluR6-deficient mice. Nature 392:601-604.

Mulle C, Sailer A, Swanson G, Brana C, O'Gorman S, Bettler B, Heine- mann S (2000) Subunit composition of kainate receptors in hippocampal interneurons. Neuron 28:475-484.

Nishimune A, Isaac JT, Molnar E, Noel J, Nash SR, Tagaya M, Collingridge GL, Nakanishi S, Henley JM (1998) NSF binding to GluR2 regulates synaptic transmission. Neuron 21:87-97.

Osten P, Srivastava S, Inman GJ, Vilim FS, Khatri L, Lee LM, States BA, Einheber S, Milner TA, Hanson PI, Ziff EB (1998) The AMPA receptor GluR2 C terminus can mediate a reversible, ATP-dependent interaction with NSF and alpha- and beta-SNAPs. Neuron 21:99-110.

Perego C, Vanoni C, Villa A, Longhi R, Kaech SM, Frohli E, Hajnal A, Kim SK, Pietrini G (1999) PDZ-mediated interactions retain the epithelial GABA transporter on the basolateral surface of polarized epithelial cells. EMBO J 18:2384-2393.

Perego C, Vanoni C, Massari S, Longhi R, Pietrini G (2000) Mammalian LIN-7 PDZ proteins associate with beta-catenin at the cell-cell junctions of epithelia and neurons. EMBO J 19:3978-3989.

Shapiro L, Colman DR (1999) The diversity of cadherins and implications for a synaptic adhesive code in the CNS. Neuron 23:427-430.

Sheng M, Pak DT (2000) Ligand-gated ion channel interactions with cytoskeletal and signaling proteins. Annu Rev Physiol 62:755-778.

Takeichi M (1988) The cadherins: cell-cell adhesion molecules controlling animal morphogenesis. Development 102:639-655.

Tanaka H, Shan W, Phillips GR, Arndt K, Bozdagi O, Shapiro L, Huntley GW, Benson DL, Colman DR (2000) Molecular modification of N-cadherin in response to synaptic activity. Neuron 25:93-107.

Tang L, Hung CP, Schuman EM (1998) A role for the cadherin family of cell adhesion molecules in hippocampal long-term potentiation. Neuron 20:1165-1175.

Tepass U, Truong K, Godt D, Ikura M, Peifer M (2000) Cadherins in embryonic and neural morphogenesis. Nat Rev Mol Cell Biol 1:91-100.

Uchida N, Honjo Y, Johnson KR, Wheelock MJ, Takeichi M (1996) The catenin/cadherin adhesion system is localized in synaptic junctions bordering transmitter release zones. J Cell Biol 135:767-779.

Vignes M, Collingridge GL (1997) The synaptic activation of kainate receptors. Nature 388:179-182.

Wenthold RJ, Trumpy VA, Zhu WS, Petralia RS (1994) Biochemical and assembly properties of GluR6 and KA2, two members of the kainate receptor family, determined with subunit-specific antibodies. J Biol Chem 269:1332-1339.

Wisden W, Seeburg P (1993) A complex mosaic of high-affinity kainate receptors in rat brain. J Neurosci 13:3582-3598. 